\title{
Histórias e memórias que brotam da terra: a educação de jovens e adultos no contexto de um assentamento rural do MST
}

M árcio H off

R esumo: Este relato pedagógico tem por objetivo demonstrar 0 processo de implementação deuma turma de jovens e adultos na modalidade EJ A em uma escola municipal, localizada no interior do Assentamento 30 de $\mathrm{M}$ aio, formada por camponeses pertencentes ao M ovimento dos Trabal hadores R urais Sem Terra-M ST, no município de Charqueadas-R S. Tem por objetivo também, relatar os aprendizados construídos pela turma a partir de uma atividade pedagógica proposta pelo educador da área de ciências sócio-históricas. Trata-se da produção e registro escrito de suas histórias de vida, os significados e ressignificações delas advindas. A culminância da atividade fez surgir um projeto para a construção do M emorial do Assentamento 30 de M aio. Com o apoio do Conselho M unicipal deCultura do município de Charqueadas, o projeto foi implementado entre setembro de 2008 a abril de 2009 e inaugurado oficialmente no dia 01 de maio de 2009 - D ia do Trabalhador.

Palavras-chave: Educação dejovens e adultos, M emória, H istórias de vida.

\footnotetext{
Professor da Turma Filhos da Terra, do A ssentamento 30 de M aio do M ST, no município de Charqueadas. Licenciado em Ciências Sociais. M estre em Sociologia das O rganizações/PU CRS, mestrando em Educação pela UFRGS e aluno do Curso de Especialização em Educação Profissional Técnica de N ível M édio Integrada a Educação Básica na M odalidade Educação de Jovens e Adultos da FACED/U FR GS. E-mail: hoffmarcio@ hotmail.com
} 


\begin{abstract}
A bstract: This report aims to demonstrate the building process of an Young and Adult Education class in a public school , inside the 30 de $M$ aio Settlement, composed by countrymen from R ural L andless Workers M ovement (M ST), in Charqueadas- R S. I t al so aims to show the learning process of this group arose from an activity proposed by the socio-historical-science teacher. This is, the writing of their own lives, the meanings and (re) meanings of it. The higher point of this activity was the creation of a project to build the 30 deM aio Settlement M emorial supported by the Cultural C ouncil of Charqueadas. The project was implemented in the period from September 2008 to A pril 2009 and officially opened on $\mathrm{M}$ ay $1^{\text {st }}, 2009$ - Workers D ay.
\end{abstract}

Keywords: Young and adult education, M emory, Life stories.

\title{
Introdução
}

D esde o surgimento do M ovimento dos Trabalhadores Rurais Sem Terra - M ST, no início da década de 80, além da luta pela reforma agrária, sempre estiveram presentes na agenda do movimento discussões sobre a conquista e a formação de escolas rurais que pudessem atender a demanda educacional dos filhos dos camponeses sem terra, através de uma pedagogia voltada para a realidade do campo e dos oprimidos da sociedade. N esse contexto, a educação popular sempre fez parte do ideário do M ST como uma das prerrogativas para consolidar o seu utópico projeto de sociedade.

Ao longo das últimas décadas, os camponeses sem terra perceberam que não bastava apenas lutar pela reforma agrária e, dessa forma, passaram a reivindicar por "escolas e, sobretudo, para cultivar em si mesmos o valor do estudo e do próprio direito de lutar pelo seu acesso a ele" (BEN JAM IN ; CALDART, 2001, p. 43). I sso aconteceu de fato a partir de 1987, quando o MST decidiu criar um setor de Educação e, a partir dele, ampliar 0 
universo de compreensão sobre o conceito de escola, pensando-a, sobretudo, como aquela que poderia criar significados para acampados e assentados a partir de uma pedagogia da terra. "A relação do M ST com a educação é, pois, uma relação de origem: a história do M ST é a história de uma grande obra educativa" (BEN JAMIN; CALDART, 2001, p. 43).

\section{Assentamento 30 de Maio e a Turma de EJA “Filhos da Terra"}

O Assentamento 30 de M aio nasceu do resultado da trajetória sócio-histórica de lutas e conflitos sociais, marcada pela incessante luta pela reforma agrária, levada a cabo por camponeses sem terra como um direito legítimo do cidadão brasileiro garantido e legitimado pela Constituição Federal brasileira. U m grupo de 46 famílias de camponeses sem terra se organizou durante três anos em acampamentos de beira de estrada conhecidos como "cidades de lona preta" e, após muitos conflitos e embates com fazendeiros e os aparelhos repressivos do Estado, conquistaram o direito de concessão de uma área de terra no município de Charqueadas e constituíram o Assentamento 30 de M aio do MST. A partir daí, as famílias camponesas passaram a organizar o seu trabalho de forma coletiva e solidária, demonstrando capacidade de organização e sobrevivência através da produção agropecuária e de hortifrutigranjeiros. Esse grupo de 46 famílias assentadas ligadas ao M ST atravessou muitas adversidades para consolidar-se como sujeitos históricos e para serem reconhecidos como agricultores que se utilizam da terra para dela tirar o seu sustento. Aos poucos, a própria comunidade do município de Charqueadas foi percebendo e reconhecendo a importância dos "colonos do assentamento", como são conhecidos na região, para o do desenvolvimento local sustentável e da economia solidária, através da produção de gêneros alimentícios livres de agrotóxicos como arroz, milho, ovos, frutas, legumes, verduras, queijo, mel, pães, leite e carne, bem como, através de atividades culturais promovidas 
pelo próprio assentamento, como confraternizações, místicas, atividades religiosas, torneios esportivos, formação política, cultural e, sobretudo, educacional. Esses elementos também contribuíram para que a comunidade passasse a admirá-los e respeitálos cada vez mais, uma vez que, no imaginário do senso comum coletivo, os integrantes do MST não passam de um bando de desordeiros.

A implementação de uma turma de Educação de J ovens e Adultos no Assentamento 30 de $M$ aio no ano de 2006, formada por camponeses pertencentes ao M ovimento dos TrabaIhadores Sem TerraM ST, deveu-se ao fato de os mesmos perce berem e compreenderem a necessidade de concluírem uma etapa dos estudos formais, como forma de viabilizar a sua participação em outros mecanismos e instâncias de inclusão e participação social. Pensando nisso, a Secretaria de E ducação do M unicípio de Charqueadas, em parceria com as Escolas M unicipais de Ensino Fundamental Pio XII e São Francisco de Assis ${ }^{1}$, o Assentamento 30 de M aio e o M ovimento dos Trabalhadores Sem Terra - M ST, através do seu Setor de Educação, priorizou atender à demanda da população residente nesse assentamento e que ainda não havia concluído as séries finais do ensino fundamental.

Em junho de 2006, uma turma de vinte e dois assentados decidiu voltar aos estudos depois de longos anos afastados da vida escolar. Com muita dificuldade foram retomando, re-aprendendo, sistematizando e ressignificando "velhos" e novos saberes. U ma das atividades pedagógicas por eles realizadas foi o registro de suas histórias de vida. A través delas, puderam compreender melhor suas trajetórias marcadas por incessantes conflitos e lutas motivadas pela esperança de conquistar um "pedaço" de terra para reconstruir suas vidas.

1 A Escola M unicipal São Francisco de Assis está localizada no interior do Assentamento 30 de $M$ aio e foi construída para atender a demanda de E ducação I nfantil e das séries inicias do Ensino Fundamental, ou seja, para atender os filhos dos camponeses que lá residem. 


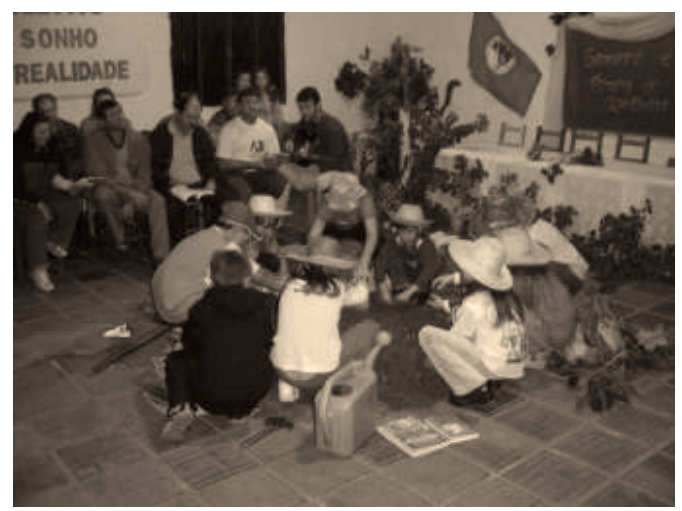

Figura 1: Aula inaugural da turma "Filhos da Terra" em 12 de junho de 2006, no Assentamento 30 de M aio do M ST.

O objetivo principal da formação de uma turma especifica na modalidade Educação de J ovens e A dultos fundamentou-se numa proposta de educação do campo que possibilitasse a esses jovens e adultos assentados, excluídos do sistema formal e regular de ensino, a oportunidade de concluir o Ensino Fundamental e construir as possibilidades legais de lhes ofertar as condições necessárias para dar continuidade aos seus estudos no Ensino M é dio. A proposta pedagógica, pensada e articulada entre todos os atores envolvidos, fundamentou-se, sobretudo, no eixo curricular articulador da Pedagogia da Alternância que, nesse processo, dialogou com questões específicas da agricultura familiar, culturas eidentidades, desenvolvimento sustentável esolidário com enfoque territorial, sistemas de produção e processos de trabalho no campo, economia solidária e cidadania, organizações e movimentos sociais e políticas públicas. Conforme R ibeiro:

a Pedagogia da A Iternância é uma expressão polissêmica queguarda elementoscomuns, mas que se concretiza de diferentes formas: conforme os sujeitos queas assumem, as regiões ondeacontecem as experiências, as condições que permitem ou limitam eatéimpedem a sua realização eas concepções teóricas que alicerçam suas práticas. Com esse cuidado e de modo 
amplo, pode-sedizer quea Pedagogia da A Iternância tem o trabalho produtivo como princípio de uma formação humanista que articula dialeticamente ensino formal e trabalho produtivo (RIBEIR 0, 2008, p. 30).

D esde o surgimento da turma, a organização do trabalho pedagógico na modalidade E ducação de Jovens e A dultos buscou integrar conhecimentos da educação geral com formação integral, por meio de metodologias adequadas à realidade dos educandos (temáticas geradoras, projetos de aprendizagem e interdisciplinares), respeitando tempos e espaços da realidade da população que a proposta pedagógica procurou atender, ou seja, os camponeses do Assentamento 30 de M aio. Para não prejudicar as atividades laborais dos agricultores que estudavam, as aulas ocorriam no turno da noitee, por escolha dos próprios educandos, janeiro e fevereiro incluíam-se como meses de aula normal no calendário escolar construído especialmente para atender às suas demandas, respeitando a obrigatoriedade das 800 horas para conclusão do Ensino Fundamental. Segundas, terças e quartas-feiras, as aulas ocorriam na escola do assentamento e, nas quintas à noite, a prefeitura disponibilizava transporte para conduzir a turma até a Escola Pio XII, no centro da cidade. Lá os educandos aprenderam novas tecnologias por meio das aulas de informática e registraram algumas de suas produções em um blog². Para propiciar a construção do conhecimento, foram priorizadas metodologias numa perspectiva dialética, na qual os educadores problematizaram o sujeito, o que os fez refletir e elaborar hipóteses. $\mathrm{N}$ esse sentido, o papel dos educadores foi o de provocar, dispor objetos, elementos, situações, interagindo com a representação do sujeito sobre o objeto de estudo, e

onde a forma de pensar totalizadora da vida seja superada dando lugar para a construção de novos elementos de conceber a vida humana de forma radical mente mais democrática elibertadora (ZITK OSK I, 2008, p. 126).

2 O blog da turma Filhos da Terra pode ser acessado no seguinte endereço: http:// filhodaterra.blogspot.com/. 
A área de conhecimento sócio-histórico abrangeu conhecimentos ligados às ciências sociais (Filosofia, $\mathrm{H}$ istória, G eografia, Sociologia, Antropologia etc.) como suportes essenciais para a realização de análises conjunturais e para a compreensão de mundo dos camponeses inseridos no processo de historicidade enquanto sujeitos históricos e sociais. N esse sentido, as ciências sócio-históricas são compreendidas como "processos de produção do conhecimento e como atividades humanas, históricas, associadas a aspectos de ordem social, econômica, política e cultural" bem como "aprofundar a relação entre conhecimento científico e o conhecimento acumulado dos trabalhadores em sua trajetória escolar, de trabalho e de vida para a construção de novos referenciais" (MINISTÉRIO DA EDU CAÇÃO, 2005, p. 30). O fato de ter a oportunidade de retomar seus estudos remeteu-os a uma reflexão sócio-histórica da sociedade brasileira para a realização de uma análise compreensiva que remontou o processo de colonização, passando pela fase de industrialização da sociedade brasileira que, em grande parte, impulsionou milhares de pequenos camponeses para as grandes cidades num processo conhecido como êxodo rural. Com relação a isso, cabem as palavras de Paulo Freire:

$\mathrm{N}$ ão são poucos os camponeses que conhecemos em nossa experiência educativa que, após alguns momentos de discussão viva em torno de um tema que lhes é problemático, param de repente e dizem ao educador: "D esculpe, nós devíamos estar calados e o senhor falando. 0 senhor é 0 que sabe; nós devíamos estar calados e o senhor falando. 0 senhor éo que sabe, nós os que não sabemos" (FREIRE, 1997, p. 50).

Partindo de uma proposta diferenciada de construção de conhecimentos, vislumbrou-se nos encontros que cada integrante do grupo de camponeses do Assentamento 30 de $M$ aio pudesse perceber-se como sujeito histórico com valores peculiares às suas histórias de vida, utilizadas constantemente para realizar as suas leituras da realidade. As aulas de conhecimento sócio-histórico pretenderam ser uma "ponte" que conduziria o aluno assentado a apropriar-se de novos saberes, tornando possível a construção de novas formas de análise dos conteúdos trabalhados em aula, 
mudando as perspectivas da "lente", buscando novos ângulos e focos de leituras e interpretação da realidade, invertendo, desta forma, a realidade dos alunos camponeses acima mencionada por Paulo Freire.

Sabe-se que o camponês é um sujeito que traz consigo uma enorme "bagagem" de conhecimentos e já passou por muitas experiências de vida. Esse fato jamais pode ser negado pelos educadores que devem procurar ensinar e aprender a partir da vida e da história de vida dos assentados. A ssim, os encontros de ciências sócio-históricas tiveram a intenção de sistematizar conhecimentos e saberes para o desenvolvimento integral do camponês assentado que estudou, através de uma proposta centrada na valorização da vida e do trabalho, numa perspectiva dialética de construção da cidadania e da historicidade.

Esses conhecimentos são necessários ao jovem e adulto trabalhador, sobretudo ao grupo de assentados que têm sua origem no M ovimento dos Trabal hadores R urais Sem Terra e compactua com os objetivos desse movimento social. H istoricamente, sabe-se que esse movimento não é bem visto "aos olhos" da sociedade que reproduz a ideologia dos segmentos conversadores da sociedade e utilizam-se dos meios de comunicação para difundir ideologias contra o MST. O caso mais recente aconteceu recentemente no Estado do R io Grande do Sul, com a tentativa de criminalização do movimento e do fechamento das escolas itinerantes por parte de setores do poder judiciário estadual. Daí, também, a necessidade dos assentados estarem balizados em novos saberes, auxiliando na desconstrução das falsas idéias que são incorporadas pelas "massas" através de versões enganosas normalmente apresentadas pelo poder midiático em que o povo está inserido. O bserve-se esta citação de Paulo Freire:

R ecentemente, num encontro público, um jovem recém-entrado na universidade me disse cortesmente: "N ão entendo como o senhor defende os sem terra, no fundo uns baderneiros, criadores de problemas". "Pode haver baderneiros entre os sem terra", disse, "mas sualuta é legítima eética". "Baderneira" é a resistência reacionária de quem se opõem a ferro e fogo 
à reforma agrária. A imoralidade e a desordem estão na manutenção de uma "ordem" injusta (FREIRE, 2002, p. 79).

E ssa fala ilustra a realidade ideológica que circunda o imaginário coletivo de grande parte da sociedade, imposta pelos segmentos sociais mais conservadores que detêm os mais importantes e legitimados meios de comunicação social.

\section{(Re)lendo o mundo através das histórias de vida}

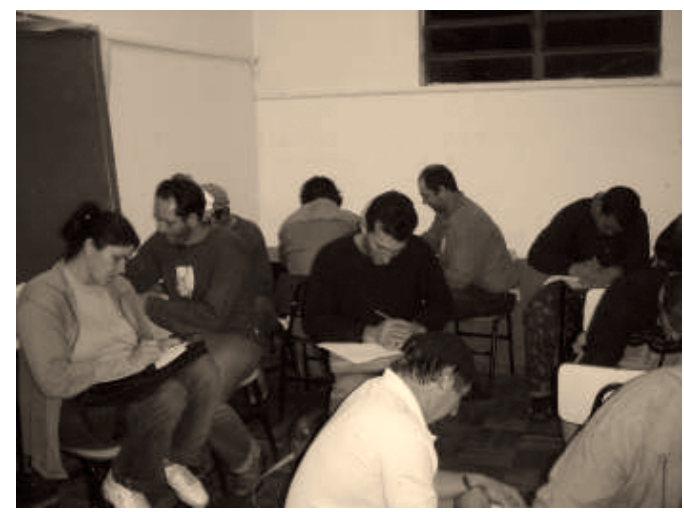

Figura 2: Educandos da turma "Filhos da Terra" em momento de registro de suas histórias devida.

Filhos de pequenos agricultores, encurralados pelo modelo econômico e agrícola excludente produzido durante a década de 70 e 80 , os vinte e dois educandos da turma "Filhos da Terra" tiveram como desafio descrever suas histórias de vida, registrando desde 0 abandono de suas famílias na região norte do R io Grande do Sul até sua organização através do MST. Suas famílias passaram por quatro anos de penosas lutas e sofrimento, acampados na beira das estradas do R io Grande do Sul, entre os anos de 1987 e 1991. Suas principais formas de luta e pressão para serem assentadas foram as ocupações em terras improdutivas, grandes caminhadas e acampamentos improvisados na Praça da 
Matriz, em Porto Alegre, como forma de sensibilizar a socie dade para a problemática dos sem terra.

A década de 80 foi um período de efervescência dos movimentos sociais, com o término da ditadura militar e a abertura política caracterizada pela redemocratização, sobretudo dos partidos políticos. Motivados pela luta de uma vida mais digna e com mais justiça social, bem como a conquista de sua própria dignidade enquanto seres humanos, os agricultores sem terra foram organizando-se com o apoio de setores da I greja católica, através dos agentes de pastoral ligados à teologia da libertação. M uitos agricultores reconheciam no M ST uma alternativa para resolver de forma organizada um de seus maiores problemas: a falta de um pedaço de terra para plantar e criar sua família com dignidade.

Foram quatro anos (1987 a 1991) de enfrentamento perma nente com o Estado e seus aparelhos repressivos, pela falta de políticas eficazes na implementação da R eforma A grária, permitindo, assim, que os sem terra identificassem quem eram os seus principais opositores. I sso fez com que até hoje algumas famílias do Assentamento 30 de Maio tragam na memória as cicatrizes e as marcas de resistência impostas pelos conflitos que ocorreram naquele período. O s confrontos mais violentos envolvendo asfamílias que hoje formam o Assentamento 30 de Maio se deram durante a ocupação da Fazenda Santa EImira, no município de Salto do J acuí, em 1989 e a ocupação da Praça da M atriz, em frente ao Palácio Piratini, no centro de Porto Alegre, no dia 08 de agosto de 1990.

O utro grande motivo que manteve os agricultores sem terra na luta pela R eforma Agrária foi a sua vocação enquanto agricultores, pois os mesmos sabiam e queriam trabalhar com a terra, já tinham um vínculo identitário com ela desde criança, trabalhando na lavoura junto com seus pais. D urante o período de acampamento, o principal objetivo dessas famílias era a luta pela terra. Esse foi um período de muita aprendizagem por parte dessas famílias, pois segundo eles, o M ST foi e continua sendo 
sua melhor escola no sentido da cooperação e da organização das famílias, práticas que já ocorriam nos acampamento.

D epois de assentados, em 30 de maio de 1991, os educandos contam que passaram a se organizar de forma coletiva com suas famílias, com base nas experiências de cooperação agrícola de outros assentamentos. Buscaram compreender melhor como cultivar e produzir na terra e decidiram que juntos poderiam facilitar as economias e adquirir os meios de produção, (bois, carroças, máquinas agrícolas e implementos) estruturando-se minimamente para iniciar a produção agrícola e melhorar suas vidas.

O sistema de cooperação agrícola adotado pelas famílias do A ssentamento 30 de $M$ ai o facilitou o acesso ao capital eà tecnologia, bem como ao desenvolvimento da produção, ao aumento da produtividade do trabalho através da organização social, à especialização e qualificação da mão-de-obra e à possibilidade de agregar valores ao que era produzido através do beneficiamento e agroindustrialização de derivados de carne, leite, frutas e verduras. N este contexto, as famílias assentadas passaram a criar meIhores condições de vida em termos de infra-estrutura social básica como energia elétrica, água potável, escola, a construção da agrovila e o acesso ao transporte. A construção da agrovila foi um dos elementos que mais aglutinou os assentados para a convivência social propiciando o desenvolvendo de valores mais coletivos.

Em suas histórias de vida, os assentados contam que 0 associativismo e o cooperativismo aparecem como estratégia para romper com a lógica da exclusão social, historicamente imposta pela sociedade capitalista, colocando a terra improdutiva nas mãos de quem nela trabalha, a fim de produzir alimentos para a sociedade ao invés de servir de mercadoria. $\mathrm{N}$ a visão dos educandos da turma "Filhos da Terra", a reforma agrária é viável e necessária para acabar com a fome e o desemprego na sociedade. D esta forma, a cooperação aparece como uma alternativa ao individualismo e, também, como um ensaio para a formação de uma sociedade mais justa e igualitária, na qual as comunidades rurais 
possam se organizar procurando libertar as pessoas do paradigma individualista imposto pela sociedade neoliberal.

Os principais objetivos a serem alcançados com a proposta do registro da história de vida dos educandos assentados foram: a) refletir e recuperar a história de vida de cada aluno jovem e adulto, procurando sistematizar essas experiências em sala de aula; b) conhecer e respeitar diferentes modos de vida, em diversos tempos e espaços, em suas mais diversas manifestações; c) oferecer instrumentos que possibilitem ao aluno questionar a sua realidade, identificando problemas sociais e refletindo a respeito de algumas de suas possíveis soluções, reconhecendo formas de atuação e organizações coletivas da sociedade civil; d) procurar sistematizar as histórias de vida dos educandos a partir de sua inserção no M ST e construir o M emorial do Assentamento 30 de Maio.

A metodologia proposta para a construção e sistematização de suas histórias de vida levou em conta os seguintes elementos pedagógicos:

- R eflexão sobre o que contam os livros didáticos de história sobre quem realmente faz, constrói e reconstrói a história das sociedades;

- Criação de roteiro para sistematização das histórias de vida;

- Sugestão de formas que pudessem ser úteis na recuperação da história de vida: desenhos, gravuras, fotos, cartazes, cartas, narrativas, poesias, etc;

- Comparação e agrupamento das histórias;

- Descrição do lugar de origem, por que entrou para o MST, em que década, etc;

- Construção de uma tabela com dados da região de origem dos alunos;

- Construção de uma linha do tempo comparando acontecimentos pessoais da histórias de vida com fatos importantes que marcaram a história a nível regional, estadual, nacional e internacional; 
- M arcação no mapa do R io Grande do Sul da trajetória percorrida pelos al unos assentados até a chegada a $\mathrm{C}$ harqueadas.

\section{Das histórias de vida à construção do Memorial do Assentamento $\mathbf{3 0}$ de Maio}

0 trabalho pedagógico realizado a partir das histórias de vida dos educandos buscou despertar uma maior conscientização e compreensão das múltiplas realidades que cercam o camponês assentado, bem como recuperar os fatos e acontecimentos históricos que marcaram sua trajetória e foram constituindo sua trajetória identitária de sujeito sem terra. Com a compreensão desta totalidade, o educador da área de Ciências Sócio-históricas incentivou os educandos a criarem um espaço no qual pudessem expor suas histórias e memórias. D essa forma, surgiu a idéia cole tiva de construir um $\mathrm{M}$ emorial através de fotos e objetos que pudesse contar a história de vida coletiva das quarenta e seis famílias que hoje constituem o Assentamento 30 de Maio.

Assim, alunos e professor decidiram, coletivamente, escrever um projeto de criação de um M emorial para o Assentamento 30 de Maio, que foi encaminhado ao Fundo M unicipal de Cultura de Charqueadas e contemplado com uma verba de $\mathrm{R} \$ 6.000,00$ para a constituição do mesmo. A justificativa para a construção do $\mathrm{M}$ emorial do Assentamento foi balisada na idéia de que o patrimônio cultural, os monumentos, museus e memoriais históricos podem ser encontrados para além dos espaços urbanos. $\mathrm{N}$ as áreas rurais há todo um patrimônio cultural que deve ser valorizado pelas suas riquezas. $\mathrm{N}$ a maior parte das vezes esse patrimônio não é valorizado como tal pela população urbana.

N esse sentido, o M emorial do Assentamento 30 de M aio constitui-se numa ferramenta que nos interroga sobre o passado, fazendo emergir experiências e lembranças que configuram novos olhares e novos sentidos ao tempo presente. De fato, 0 
Memorial do Assentamento 30 de M aio, criado a partir das histórias de vida dos alunos da turma de EJA "Filhos da Terra", pode ser considerado um poderoso instrumento de educação patrimonial no meio rural, sendo utilizado como recurso para a recuperação da auto-estima e da identidade sem terra das famílias assentadas.

Para E cléa Bosi (1979), o passado faz ressurgir através da memória, elementos que se fundem com as percepções do presente, ocupando espaços importantes da nossa consciência. Para ela, é a partir de nossas experiências passadas que passamos a dar sentido aos acontecimentos do presente.

N esse contexto, nossas experiências passadas é que dão sentido aos acontecimentos presentes, que não podem existir sem que tenha havido o passado, demonstrando que somos totalmente influenciados por aquilo que já vivemos. É a partir daí que, segundo Bosi, o passado está sempre atuando em nossas vidas e nos esquemas de comportamento que utilizamos no presente.

Assim, o projeto do Memorial do Assentamento 30 de Maio tem como objetivo cristalizar-se numa narrativa da própria experiência das famílias que constituem o Assentamento 30 de $M$ aio, retomada a partir dos fatos significativos que vêm à sua lembrança. Para os alunos assentados, o M emorial consiste na possibilidade real de visualizar sua própria histórica coletiva, através de suas trajetórias de vida, ressignificando suas identidades e refletindo sobre 0 presente.

Entende-se que o M emorial tem uma função pedagógicoformativa na medida que o seu processo de elaboração e reelaboração ao longo da história do Assentamento - como um exercício contínuo e gradativo - auxiliará as famílias assentadas no desenvolvimento e na articulação dos nexos entre a sua vivência de atuação social e sua trajetória histórica de modo a gerar uma interpretação crítica de suas experiências de vida e da própria realidade que as cerca.

Para Kenski (1994) o trabalho de rememoração realizado junto aos sujeitos sociais de um determinado segmento social ou 
categoria pode trazer pistas importantes sobre sua atuação na sociedade, fornecendo elementos para a compreensão dos vários aspectos constitutivos de sua história de vida. 0 trabalho da memória é uma alternativa possível para o processo de formação dos agricultores assentados, o que já foi realizado com êxito durante os dois anos em que esses vinte e dois agricultores homens e mulheres - do Assentamento desafiaram a si próprios a retornar aos bancos escolares após longos anos afastados da escola. Esses momentos de encontros pedagógicos nas aulas de Ciências Sócio-H istóricas foram essenciais para desenvolver um trabalho de história baseado nas histórias de vida desses sujeitos sociais, até surgir a ideia coletiva da construção do M emorial do Assentamento 30 de M aio. Essa proposta foi discutida e debatida, pois, além de contar suas histórias e trajetórias de vida, sua execução poderia trabalhar no resgate da identidade coletiva do Assentamento.

No caso do Memorial do Assentamento 30 de Maio, os vinte e dois educandos que tiveram a ideia de deixar registradas suas memórias, bem como famílias assentadas e também todos aqueles que visitarem o espaço cultural, poderão tomar consciência, a partir da exposição fotográfica, documental e de objetos históricos, do universo político-social ao qual a mostra cultural está se referindo. Poderão saber em que contexto sócio-histórico os fatos ocorreram, quem são os agentes sociais envolvidos no processo, o que desenvolveram em prol da comunidade charqueadense ao longo dos seus dezoito anos de existência no município, suas principais contribuições sociais, culturais e econômicas, qual o envolvimento eo apoio recebido da comunidade de Charqueadas no início do Assentamento, quais as práticas e ações atuais desenvolvidas pelo Assentamento, seu envolvimento com o Poder Público e a comunidade em geral. As durezas, os sofrimentos e as alegrias dessas famílias, via de regra, serão narradas através do M emorial como experiências e vivências de uma época em um determinado espaço sócio-geográfico. 


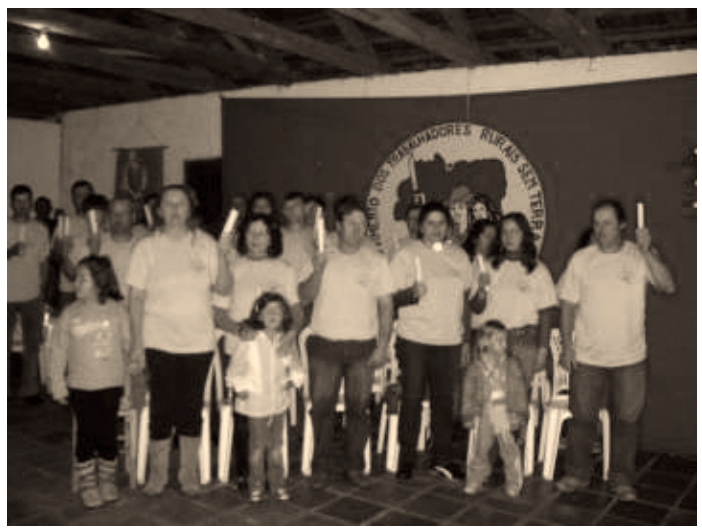

Figura 3: Cerimônia de formatura do Ensino Fundamental da turma "Filhos da Terra", no dia 12 de setembro de 2008, no Assentamento 30 de M aio.

O M emorial do Assentamento 30 de M aio foi sendo projetado pelos alunos durante o período em que escreviam suas histórias de vida. Através dele, a comunidade charqueadense e da região carbonífera, bem como os grupos que semanalmente visitam o Assentamento, terão uma maior visibilidade e entendimento do processo sócio-histórico que culminou com o surgimento do Assentamento. Essa visibilidade concretiza-se com o sonho da implementação do M emorial, pois através dele o público visitante poderá ampliar seu conhecimento sobre a história do local e das famílias que o compõem, por meio da exposição fotográfica, de palestras, vídeos sobre o Assentamento e outros artefatos que fazem parte da história de luta, sofrimentos, derrotas e conquistas, bem como constatar como vivem essas famílias atualmente. Pretende também demonstrar os benefícios econômicos e culturais que o Assentamento trouxe para Charqueadas, contribuindo com o desenvolvimento econômico, social ecultural do município, lutando pela defesa dos princípios de uma sociedade mais justa e fraterna para todos. Com isso, aspira-se ao fortalecimento do sentimento de cidadania, a recuperação da história de vida do Assentamento 30 de $\mathrm{M}$ aio e a valorização da herança cultural e identitária dessas quarenta e oito famílias que há 
dezoito anos adotaram o município de Charqueadas para construir sua história de vida e trabalho.

\section{Considerações finais}

Visitar o M emorial do Assentamento 30 de M aio representa fazer uma viagem a um passado recente que procura estabelecer relações entre a vida no campo e a luta pela dignidade humana de quem se humilhou e sofreu para conquistar um pedaço de terra de forma legítima, assegurada em lei pela constituição brasileira. Durante as visitas organizadas, um membro do Assentamento sempre está à disposição dos visitantes para explicar a história e a saga das quarenta e seis famílias que, com suor e muita luta, fundaram o Assentamento 30 de $\mathrm{M}$ aio. 0 M emorial tem uma exposição de fotos ampliadas seguindo uma ordem cronológica, exposição de objetos, artefatos e documentos que as famílias preservaram ao longo dos anos como valor histórico e sentimental. Além do que já foi dito, o $\mathrm{M}$ emorial tem uma representabilidade valiosa para os grupos e segmentos sociais que semanalmente visitam o Assentamento com o objetivo de conhecer a história de trabal hadores e trabal hadoras rurais que lutaram durante anos em busca da realização de seu sonho, ou seja, em busca da conquista de um pedaço de terra. Também funciona como um valioso instrumento que irá facilitar a visualização e o entendimento do processo sócio-histórico da luta e da conquista legítima da terra e da organização do Assentamento 30 de Maio, símbolo de orgulho para a comunidade Charqueadense. A organização de eventos culturais de forma isolada ou em parceria com as Secretarias M unicipais de Cultura, Educação, E conomia Solidária e Q ualidade A mbiental também fazem parte dos trabalhos desenvolvidos como forma de retorno social ao investimento financeiro realizado pelo Fundo Municipal de Cultura de Charqueadas. Para citar a importância cultural do Assentamento 30 de $M$ aio, basta nos reportarmos ao ano de 2002, quando, durante a realização do III Fórum Social M undial, ocorreram 
oficinas pedagógicas e debates com a presença de personalidades internacionais como a médica A leida Guevara, filha de Ernesto Che Guevara, o ambientalista francês José Bové e a representante das $\mathrm{M}$ ães da Praça de $\mathrm{M}$ aio, $\mathrm{H}$ ebe de Bonafini, para o lançamento da campanha "Sementes, Patrimônio da H umanidade".

$\mathrm{N}$ a época, a V ia Campesina escolheu o Assentamento 30 de M aio para construir o "Bosque da L uta e da Solidariedade" e para o lançamento da campanha "As sementes são patrimônio da humanidade". O evento aconteceu em 26 de janeiro, durante o III Fórum Social M undial. M ais de dois mil presentes, entre camponeses e apoiadores da V ia Campesina, assistiram aos depoimentos em defesa da preservação das sementes e contra a apropriação dos recursos genéticos da humanidade por empresas multinacionais. R afael Alegria ( V ia Campesina), J osé Bové (Confederação Camponesa da França), H ebe Bonafini ( $M$ ães da Praça de $M$ aio) e a internacionalista A leida Guevara falaram aos participantes. Durante o ato, sementes foram distribuídas aos participantes e árvores foram plantadas, representando os cinco continentes. O s presentes partici param de um al moço de confraternização com produtos dos assentamentos de reforma agrária. 0 intelectual norte-americano N oam Chomsky (MIT - Instituto de Tecnologia de M assachusettz) foi um dos participantes do lançamento. Chomsky também plantou uma árvore no Bosque da Solidariedade e da L uta e comparou a situação vivida pelos camponeses na Colômbia, "um lugar onde não há o M ST".

Com relação às possibilidades de continuidade dos estudos de nível médio da turma "Filhos da Terra", uma pesquisa realizada com os vinte e dois educandos que concluíram o ensino fundamental constatou que a maior parte deles deseja continuar seus estudos por meio da realização de um curso técnico profissionalizante na área rural. N esse sentido, o Setor de Educação do Assentamento 30 de M aio e a U nidade do CEFET - Centro Fe deral de Educação Tecnológica, em Charqueadas, estão unidos na busca de uma alternativa para viabilizar a formação de um curso que atenda aos interesses e demandas dos jovens e adultos 
assentados, através do PROEJA - Programa N acional de Integração da E ducação Profissional com a E ducação Básica na M odalidade da E ducação de J ovens e Adultos.

\section{Referências}

BEN JAM IN , César; CA LD ART, R oseli. Projeto Popular eE scolasdoC ampo: por uma educação básica do campo. Braślia: A rticulação $\mathrm{N}$ acional por uma educação básica no campo, 2001.

BO SI, Ecléa. M emória e Sociedade: lembranças dos velhos. São Paulo: Companhia das L etras, 1979.

FR EIR E, Paulo. Pedagogia da A utonomia: saberes necessários à prática educativa. São Paulo: Paz e Terra, 2002. . Pedagogia do O primido. São Paulo: Paz e Terra, 1997.

K EN SK I, Vani M oreira. M emória e ensino. In: C adernos de pesquisa. São Paulo, n. 90, ago. 1994.

M IN ISTÉR IO DA EDU CAÇÃO. Saberes da terra. Programa N acional de Educação de Jovens e A dultos I ntegrada com Q ualificação Social e Profissional para Agricultores (As) Familiares. B rasília: Secretaria daE ducação Continuada, A Ifabetização e D iversidade. Secretaria da E ducação Profissional e Tecnológica, 2005.

RIBEIR O, M arlene. Trabalho agrícola e educação escolar: a pedagogia da alternância como alternativa à educação rural. Educação e Pesquisa, São Paulo, v. 34, n.1, p. 27-45, jan./abr. 2008.

ZITKOSKI, Jaime; STR ECK, D anilo; RED IN , Euclides (O rgs.) D icionário Paulo Freire. Belo H orizonte: Autêntica, 2008. 